\title{
Analysis of Adjacent Fractures after Two-Level Percutaneous Vertebroplasty: Is the Intervening Vertebral Body Prone to Re-fracture?
}

\author{
Seok Han, Il-Tae Jang \\ Department of Neurosurgery, Gangnam Nanoori Hospital, Seoul, Korea
}

\section{Study Design: Retrospective study.}

Purpose: This retrospective study aimed to determine the incidence of adjacent level new fractures in a sandwich constellation (one or two untreated vertebrae between two cemented vertebrae) compared with that in other constellations formed by two-level percutaneous vertebroplasty (PVP). It also aimed to investigate the potential factors contributing to adjacent new fractures in a sandwich constellation.

Overview of Literature: There are few studies regarding the intervening intact vertebral body between two cemented vertebrae. Clinical data from previous studies investigation this sandwich situation, too, have been vague.

Methods: Clinical data were obtained from 132 patients who had two cemented vertebral bodies, irrespective of whether they had undergone one or two PVP sessions between January 2013 and June 2016 at a single institution. Cases with one or two intact vertebral levels between the two cemented vertebrae were classified into group $1(n=47)$, and cases with two consecutive cemented bodies or more than three levels of intervening configurations were classified into group 2 ( $n=85$ ). Demographic data and radiological parameters for new fractures after PVP were compared between the two groups, and the rates of subsequent adjacent fractures were investigated.

Results: The incidence of single-level sandwich constellations was quite uncommon (7.7\%). The overall incidences of adjacent fracture were $29.8 \%(14 / 47)$ in group 1 and $14.1 \%(12 / 85)$ in group 2 . This difference was statistically significant $(p=0.03)$. Approximately $80 \%(11 / 14)$ of the adjacent new fractures in group 1 developed at an intervening level. The patient demographics and radiological parameters for subsequent fractures after PVP did not statistically correlate with the risk of adjacent new fractures in group 1. Conclusions: Because they were subjected to double-load shifts, sandwich constellations were prone to re-fractures after PVP. These vertebral configurations required more aggressive management for osteoporosis.

Keywords: Intervening vertebral body; Sandwich constellation; Adjacent-level fracture; Vertebroplasty

\section{Introduction}

Percutaneous vertebroplasty (PVP) is an efficient proce- dure for treating pain caused by vertebral osteoporotic compression fractures (OCFs). Although PVP is a minimally invasive procedure for patients with painful OCFs

Received May 21, 2017; Revised Sep 5, 2017; Accepted Sep 30, 2017

Corresponding author: Il-Tae Jang

Department of Neurosurgery, Gangnam Nanoori Hospital, 731 Eonju-ro, Gangnam-gu, Seoul 06048, Korea

Tel: +82-10-8634-6726, Fax: +82-32-514-0210, E-mail: torcula@naver.com 
[1-5], previous studies have shown that the incidence of subsequent new cases of OCF was approximately $12 \%-52 \%$ [6-10]. These new fractures often occur in adjacent vertebral bodies [8,10,11-15]. Feasible reasons for these new fractures include preexisting bone fragility in osteoporotic patients, immediate increases in stiffness and strength of the treated vertebral body, and improved mobility that causes a new load on vertebral bodies [7$10,12-15]$. In addition, there is an extensive debate regarding whether PVP is associated with subsequent OCF, and several risk factors have been hypothesized $[6-10,16]$. However, there are few studies regarding whether the intervening intact vertebral body between two previously cemented vertebrae is a risk factor for the third vertebral OCF [17]. Clinically, we have infrequently observed these characteristic vertebral configurations formed by PVP. Hence, we questioned whether an increased vulnerability to postoperative adjacent-level fracture caused by load shift would be maximized in the intervening vertebra that must doubly sustain the load shift.

It is generally accepted that polymethyl methacrylate (PMMA) injection strengthens the vertebrae to withstand a higher axial compressive force prior to fracture and stiffens the cemented vertebrae beyond its initial stiffness [18]. However, whether vertebral PMMA augmentation increases the vulnerability of adjacent vertebrae to fractures and the mechanisms involved in new OCFs at adjacent levels are not well understood [18]. Polikeit et al. [19] reported that PMMA augmentation restores the strength of treated vertebrae but results in higher loading on the adjacent vertebral bodies as well as increased pressure on the nucleus pulposus. Pressure changes in the nucleus pulposus lead to an enlarged deflection of the endplate into the adjacent untreated vertebra. This finding supports the hypothesis that rigid PMMA augmentation may facilitate subsequent collapse of adjacent vertebral bodies at significantly lower spinal loads $[12,19]$.

This retrospective study aimed to determine the incidence of adjacent-level new fractures in sandwich constellations compared with that in other constellations formed by two-level PVPs. It also aimed to investigate the factors that potentially contribute to adjacent new fractures in a sandwich constellation. This study may help clarify the debate on adjacent-level fractures after multi-level PVP.

\section{Materials and Methods}

The Institutional Review Board of Gangnam Nanoori Hospital approved this retrospective study (IRB approval no., NR-IRB 2016-008) and waived the requirement for informed consent. A total of 388 patients with 457 symptomatic OCFs were consecutively treated with PVP at a single institution between January 2013 and June 2016. Patients who received fusion surgery adjacent to the fractured level or had underlying diseases other than benign OCF, such as metastasis or malignancy, were excluded from the study. The diagnosis was confirmed using magnetic resonance imaging (MRI), which depicts bone marrow edema even in the absence of or only incipient height loss. MRI was performed using a 1.5-Tesla system (Signa HDxt or Signa Hde; GE Medical Systems, Milwaukee, WI, USA) with sagittal short-tau inversion recovery (STIR) and a T1-weighted spin echo sequence. When a signal increase was either diffuse or near the endplate in STIR sequences and when there was a respective signal loss in the corresponding T1-weighted images, vertebral bodies proved positive for bone marrow edema. Patients with two cemented vertebral bodies or a history of two-level PVP, irrespective of whether they had undergone one or two PVP sessions, were selected and retrospectively enrolled in this study ( $\mathrm{n}=132)$. All procedures were performed by the same team after obtaining a detailed standardized history. Brace protection was suggested to all patients for $\geq 3$ months after PVP. A chairback brace for fractures below the L3 level and a Taylor brace for fractures above the L3 level or at the thoracic spine region were recommended.

The four kinds of vertebral configurations formed by two levels of PVP were as follows: (1) one intact vertebral body intervening between two cemented vertebrae, (2) two intact bodies intervening, (3) two consecutive levels of cemented vertebrae, and/or (4) more than three levels intervening between the two cemented vertebrae. Cases with one or two intact levels intervening between the cemented vertebrae were classified into group $1(n=47)$, and the remaining two configurations were classified into group 2 $(\mathrm{n}=85)$ (Fig. 1). Preoperative clinical research data were retrospectively collected from the medical records and were assembled into a database by one of the authors $(\mathrm{SH})$.

The rates of subsequent adjacent vertebral fractures between the two groups were investigated. A demographic database including patient age, sex, body weight, T-score from bone densitometry (bone mineral density [BMD]), 

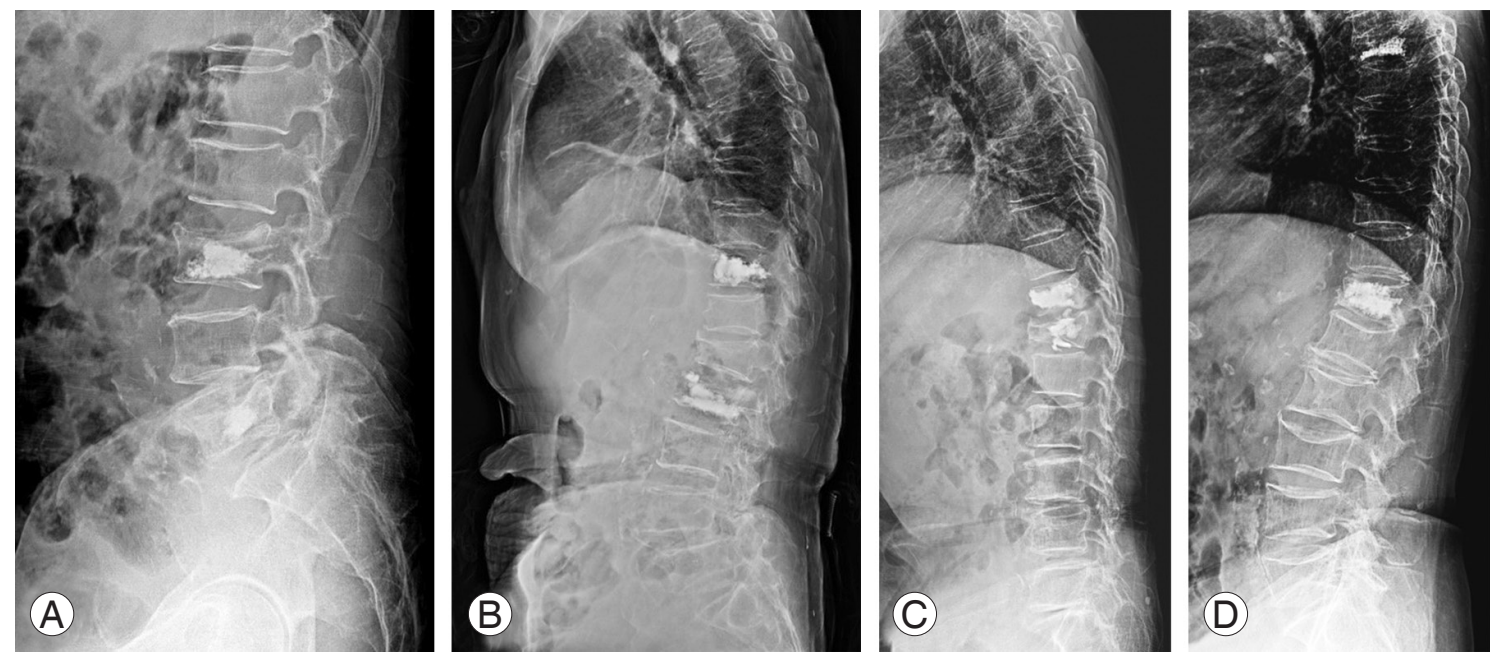

Fig. 1. Cases with one or two intact vertebral levels intervening between cemented vertebrae were classified into group 1 (A, B) and those with two consecutive levels between two cemented vertebrae or more than three levels intervening between two cemented vertebrae were classified into group 2 (C, D).

location of intervening level (thoracic, T10-L2, or lumbar), presence or absence of the intravertebral cleft (IVC), use of teriparatide, use of bisphosphonates or selective estrogen receptor modulators, trauma history after vertebroplasty in the case of new fractures, interval to an adjacent new fracture, and follow-up interval was created. Considering that adjacent fractures mainly occur within 2 years (typically within 4 months, according to previous studies) $[5,8,14,16,20]$, the maximal follow-up interval was limited to 24 months. Furthermore, remote fractures were not included in this study because the mechanisms of adjacent and remote fractures vary $[11,20]$ and adjacent fractures occur earlier than remote fractures after cement augmentation caused by a direct effect $[8,9]$.

The occurrence of an adjacent new fracture was determined by reviewing medical records and imaging studies of 59 cases. Furthermore, follow-up was conducted via phone calls to the patients who did not revisit the hospital after the PVP procedure. Telephonic interviews were conducted by a third party, which was blinded to the groupings and was not involved in the treatment or study.

Surgical variables included the number of sessions (one or two), PMMA injection procedure (PVP or balloon kyphoplasty), injected cement volume for each treated vertebral body (superior and inferior), surgical approach (through uni- or bilateral pedicles), and cement leakage into the intervertebral disc space. In addition, the anterior vertebral height restoration rate (superior and inferior), wedge angle with postoperative angle change (superior
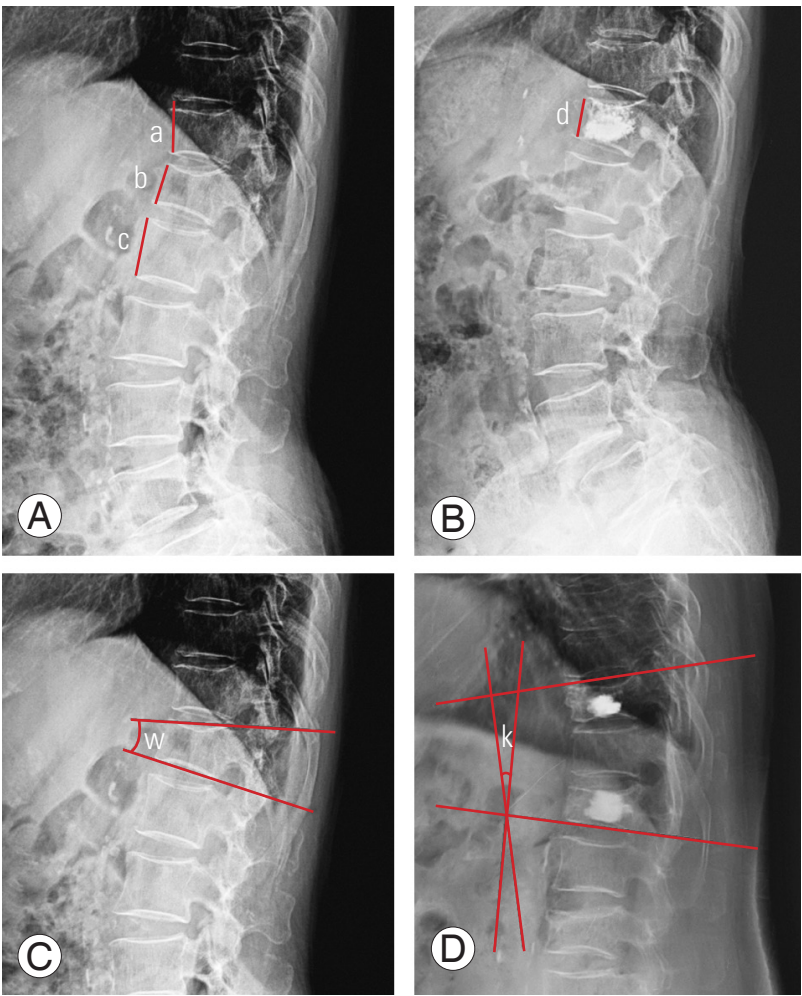

Fig. 2. (A-D) Method used for determining anterior vertebral height restoration rate. Anterior vertebral body height before compression fracture $(e): e=(a+c) / 2$. Anterior height restoration rate $(R): R=d-b /$ ex100 (\%). Methods of estimating wedge angle (w) and kyphotic angle (k).

and inferior), and pre- and postoperative kyphotic angulation of the intervening region were measured and calculated in a conventional manner (Fig. 2). For the 
calculations of vertebral height restoration rate, vertebral body pre-fracture heights were assumed to be equal to the averages of the heights of the adjacent vertebrae, and heights were then expressed as percentages of presumed normal heights before and after PVP [21]. The wedge angle was defined as the angle between the superior and the inferior endplate line of the fractured vertebral body [22]. The pre- and postoperative kyphotic angles of the affected segments were defined as the measured angle between the superior endplate of the upper vertebra and the inferior endplate of the lower vertebra, as indicated on sagittal radiographs [18]. Determination of cement leakage into the disc space and measurements of the height restoration rate, wedge angle, and sagittal kyphotic angulation were performed by a single observer (SH).

All statistical analyses were performed using the SPSS ver. 16.0 software (SPSS Inc., Chicago, IL, USA). Data were presented as mean \pm standard deviation. Univariate and multivariate binary logistic regression analyses were used to determine if the individual factors were independently associated with a subsequent adjacent fracture. All $p<0.05$ were considered statistically significant.

\section{Results}

The incidences of single- and double-level sandwich con- stellations were $7.7 \%(30 / 388)$ and $4.4 \%(17 / 388)$, respectively. No statistically significant differences were observed in the incidences of new fractures between the subgroups in either group 1 ( $p=0.966$ by the chi-square test) or group 2 ( $p=0.306$ by the Fisher's exact test).

The characteristics of patients in group 1 and group 2 are listed in Table 1 . There were significantly more males in group $1(19.1 \%)$ than in group $2(7 \%)(p=0.036)$. The surgical variables and radiological parameters are listed in Table 2. The preoperative wedge angle of the inferior fractured vertebral body was observed to be significantly higher in group 2 than in group $1(p=0.005)$.

In group 2, which included 85 patients with 170 fractures, 12 adjacent fractures with a new onset of pain ranging from 1 to 17 months after PVPs were identified. In group 1, which included 47 patients with 94 vertebrae treated with PVPs, 14 patients had adjacent levels that developed third vertebral fatigue fractures ranging from 15 days to 20 months. Approximately $80 \%$ (11/14) of the adjacent new fractures in group 1 developed at an intervening level. Adjacent fractures developed at the inferior body to the inferior cemented vertebra in two cases and at the superior body to the superior cemented vertebra in one case. Among 14 patients, 10 underwent additional PVP for symptom control. The remaining four were treated with conservative management.

Table 1. Summary of the characteristics of patients in group 1 and group 2

\begin{tabular}{|c|c|c|c|c|}
\hline Characteristic & Group $1(\mathrm{n}=47)$ & Group $2(\mathrm{n}=85)$ & $X^{2}$ & $p$-value \\
\hline Age (yr) & $76.45 \pm 8.61$ & $76.68 \pm 7.84$ & & $0.873^{\mathrm{a})}$ \\
\hline Male:female (male\%) & $9: 38$ (19.1) & $6: 79(7.0)$ & 4.392 & $0.036^{b)}$ \\
\hline Body weight $(\mathrm{kg})$ & $55.62 \pm 9.97$ & $52.73 \pm 9.92$ & & $0.114^{\mathrm{a})}$ \\
\hline Thoracic:TLJ:Iumbar (TLJ\%) & $2: 27: 18(60.0)$ & $9: 55: 21(64.0)$ & 3.422 & $0.192^{c)}$ \\
\hline T-score & $-4.74 \pm 1.47$ & $-4.56 \pm 1.84$ & & $0.568^{a)}$ \\
\hline Intravertebral cleft & $5(10.6)$ & $14(16.5)$ & 0.84 & $0.361^{b)}$ \\
\hline PVP session (2:1, 1 session\%) & $30: 17(36.0)$ & $53: 32(37.6)$ & 0.028 & $0.866^{b)}$ \\
\hline No. of PVP/percutaneous kyphoplasty & $44: 3(93.6)$ & $77: 8(90.6)$ & 0.363 & $0.746^{c)}$ \\
\hline No. of unilateral/bilateral & $12: 35(74.5)$ & $21: 64(75.3)$ & 0.011 & $0.916^{b)}$ \\
\hline Teriparatide use & $3: 44(6.4)$ & $5: 80(5.9)$ & 0.013 & $1.000^{c)}$ \\
\hline Bisphosphonate or selective estrogen receptor modulator use & $32: 15(68.0)$ & $64: 21(75.3)$ & 0.793 & $0.373^{b)}$ \\
\hline Trauma history & $4: 10(28.6)$ & $4: 8(33.3)$ & 0.069 & $1.000^{c)}$ \\
\hline Follow-up interval (mo) & $14.5 \pm 9.71$ & $17.33 \pm 7.73$ & & $0.090^{a)}$ \\
\hline
\end{tabular}

Values are presented as mean \pm standard deviation or number (\%).

TLJ, thoracolumbar junction; PVP, percutaneous vertebroplasty.

${ }^{\text {al }}$ Comparison made by performing Student $t$-test. ${ }^{b /}$ Comparison made by performing the chi-square test. ${ }^{c}$ Comparison made by performing Fisher's exact test. 
Table 2. Summary of the surgical and radiological parameters of group 1 and group 2

\begin{tabular}{|c|c|c|c|c|}
\hline Variable & Group $1(\mathrm{n}=47)$ & Group $2(n=85)$ & $X^{2}$ & $p$-value \\
\hline Superior inject volume (mL) & $4.81 \pm 1.62$ & $4.77 \pm 1.60$ & & $0.887^{a)}$ \\
\hline Inferior inject volume (mL) & $5.29 \pm 1.44$ & $5.16 \pm 1.58$ & & $0.661^{\text {a) }}$ \\
\hline Discal leakage (leakage rate) & $16: 31(34.0)$ & $24: 61(28.2)$ & 0.483 & $0.487^{b)}$ \\
\hline Superior height restoration rate (\%) & $5.46 \pm 7.28$ & $5.36 \pm 7.52$ & & $0.943^{\mathrm{a})}$ \\
\hline Inferior height restoration rate (\%) & $4.93 \pm 7.04$ & $5.13 \pm 7.07$ & & $0.879^{a)}$ \\
\hline Superior wedge angle $\left(^{\circ}\right)$ & $10.36 \pm 5.36$ & $9.49 \pm 5.56$ & & $0.391^{\mathrm{a})}$ \\
\hline Superior wedge angle change $\left({ }^{\circ}\right)$ & $2.27 \pm 3.22$ & $1.85 \pm 2.40$ & & $0.400^{\mathrm{a})}$ \\
\hline Inferior wedge angle $\left(^{\circ}\right)$ & $5.89 \pm 4.09$ & $8.55 \pm 5.45$ & & $0.005^{\mathrm{a})}$ \\
\hline Inferior wedge angle change $\left(^{\circ}\right)$ & $1.86 \pm 2.41$ & $2.06 \pm 2.80$ & & $0.688^{\mathrm{a})}$ \\
\hline Mean preoperative kyphotic angle $\left(^{\circ}\right)$ & $16.96 \pm 9.95$ & $15.80 \pm 9.48$ & & $0.510^{\mathrm{a})}$ \\
\hline Mean postoperative kyphotic angle $\left(^{\circ}\right)$ & $14.29 \pm 9.90$ & $13.33 \pm 8.81$ & & $0.568^{\text {a) }}$ \\
\hline
\end{tabular}

Values are presented as mean \pm standard deviation or number (\%).

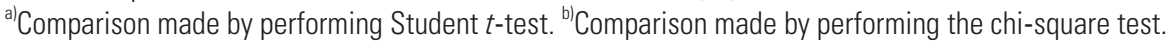

Table 3. Comparison of the adjacent new fracture rates in group 1 and group 2

\begin{tabular}{lcccc} 
Variable & Group $1(\mathrm{n}=47)$ & Group $2(\mathrm{n}=85)$ & Total & $p$-value \\
New adjacent fracture & $14(29.8)$ & $12(14.1)$ & 26 & $0.030^{\mathrm{a})}$ \\
No adjacent fracture & 33 & 73 & 106 & \\
\hline Total & 47 & 85 & 132 \\
\hline
\end{tabular}

Values are presented as number (\%) or number.

${ }^{a}$ Comparison made by performing the chi-square test.

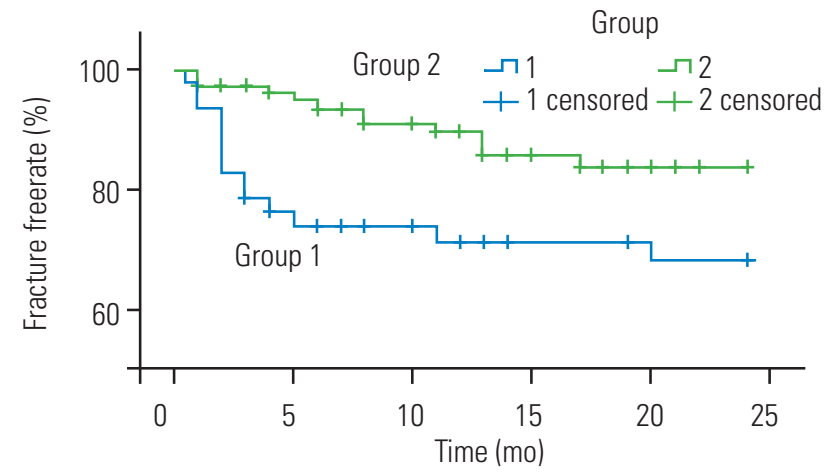

Fig. 3. Kaplan-Meier survival curve depicting the estimated fracturefree rate of adjacent vertebrae after percutaneous vertebroplasty in group 1 and group 2. Also shown is the distinct difference in the fracture-free rates between the two groups.

The overall cohort incidence of adjacent new fractures in group 1 was $29.8 \%$ (14/47), which was significantly higher than that in group $2(14.1 \%, 12 / 85 ; p=0.030)$ (Table 3). This finding was also verified using the Kaplan-Meier curves (Fig. 3). The Kaplan-Meier estimates of the 2-year fracture-free rates after PVP in groups 1 and group 2 were
$68.3 \%$ and $85.3 \%$, respectively. Group 1 was at a higher risk of adjacent new fractures than group 2 ( $p=0.017$, logrank test).

Table 4 shows that the patient demographics did not statistically correlate with the risk of an adjacent new fracture in group 1. Furthermore, no radiological evaluation values were related to the occurrence of an adjacent new fracture in group 1 . The available variables that were used in multiple logistic regression analysis included age, Tscore, discal leakage, injected PMMA volume, and all the radiological parameters. No variable was positively associated with an adjacent new fracture in group 1.

\section{Discussion}

There have been numerous investigations concerning adjacent vertebral fractures subsequent to vertebral augmentation procedures using PMMA [5-10]. The reported incidence rate of adjacent vertebral fracture after PVP appears to increase from $12 \%$ at 2 years [10] to $52 \%$ at 4 years [6] with follow-up. Although the cause and develop- 
Table 4. Summary of patient characteristics and surgical and radiological parameters of group 1

\begin{tabular}{|c|c|c|c|c|}
\hline Characteristic & No adjacent Fx. (n=33) & Adjacent Fx. $(n=14)$ & $X^{2}$ & $p$-value \\
\hline Age (yr) & $77.09 \pm 8.60$ & $74.93 \pm 8.75$ & & $0.437^{\mathrm{a})}$ \\
\hline Male:female (male\%) & $5: 28(15.1)$ & $4: 10(28.6)$ & 1.143 & $0.419^{b l}$ \\
\hline Body weight $(\mathrm{kg})$ & $55.85 \pm 10.52$ & $55.07 \pm 8.89$ & & $0.810^{\mathrm{al}}$ \\
\hline Thoracic:TLJ:Iumbar (TLJ\%) & $2: 20: 11(60.6)$ & $0: 7: 7(50.0)$ & 1.409 & $0.470^{\mathrm{bl}}$ \\
\hline T-score & $-4.96 \pm 1.32$ & $-4.24 \pm 1.72$ & & $0.130^{\text {a) }}$ \\
\hline Intravertebral cleft & $3(9.1)$ & $2(14.3)$ & 0.28 & $0.627^{b)}$ \\
\hline PVP session (2:1, 1 session \%) & $23: 10(30.3)$ & $7: 7(50.0)$ & 1.652 & $0.199^{c)}$ \\
\hline No. of PVP/percutaneous kyphoplasty & $30: 3(90.9)$ & $14: 0(100.0)$ & 1.360 & $0.544^{\text {b) }}$ \\
\hline No. of unilateral/bilateral & $8: 25(75.8)$ & $4: 10(71.4)$ & 0.097 & $0.731^{b)}$ \\
\hline Teriparatide use & $3: 30(9.1)$ & $0: 14(0)$ & 1.360 & $0.544^{\text {b) }}$ \\
\hline Bisphosphonate or selective estrogen receptor modulator use & $22: 11(66.7)$ & $10: 4(71.4)$ & 0.103 & $1.000^{b)}$ \\
\hline Superior inject volume $(\mathrm{mL})$ & $4.70 \pm 1.74$ & $5.11 \pm 1.30$ & & $0.507^{\text {a) }}$ \\
\hline Inferior inject volume (mL) & $5.21 \pm 1.26$ & $5.49 \pm 1.85$ & & $0.572^{\text {a) }}$ \\
\hline Discal leakage (leakage rate) & $10: 23(30.3)$ & $6: 8(42.9)$ & 0.690 & $0.506^{b)}$ \\
\hline Superior height restoration rate $(\%)$ & $5.59 \pm 7.72$ & $5.12 \pm 6.31$ & & $0.847^{\text {a) }}$ \\
\hline Inferior height restoration rate (\%) & $4.32 \pm 6.55$ & $6.48 \pm 8.24$ & & $0.356^{\text {a) }}$ \\
\hline Superior wedge angle $\left(^{\circ}\right)$ & $10.05 \pm 5.25$ & $11.16 \pm 5.78$ & & $0.532^{\text {a) }}$ \\
\hline Superior wedge angle change $\left({ }^{\circ}\right)$ & $2.19 \pm 3.05$ & $2.48 \pm 3.73$ & & $0.792^{\text {a) }}$ \\
\hline Inferior wedge angle $\left(^{\circ}\right)$ & $6.10 \pm 4.42$ & $5.35 \pm 3.19$ & & $0.584^{\text {a) }}$ \\
\hline Inferior wedge angle change $\left(^{\circ}\right)$ & $1.64 \pm 2.14$ & $2.39 \pm 2.97$ & & $0.338^{\text {a) }}$ \\
\hline Mean preoperative kyphotic angle $\left({ }^{\circ}\right)$ & $17.76 \pm 10.22$ & $14.93 \pm 9.32$ & & $0.391^{\text {a) }}$ \\
\hline Mean postoperative kyphotic angle $\left({ }^{\circ}\right)$ & $15.23 \pm 10.46$ & $12.08 \pm 8.33$ & & $0.323^{\text {a) }}$ \\
\hline
\end{tabular}

Values are presented as mean \pm standard deviation or number (\%).

Fx., fracture; TLJ, thoracolumbar junction; PVP, percutaneous vertebroplasty.

${ }^{\text {a) }}$ Comparison made by performing Student $t$-test. ${ }^{b}$ Comparison made by performing Fisher's exact test. ${ }^{\text {c) }}$ Comparison made by performing the chisquare test.

ment of adjacent vertebral fracture subsequent to PVP has been investigated in several studies, it has not yet been determined if PVP itself causes the fracture. No study has directly compared the adjacent vertebral fracture rate after the most popular conservative management with that after operative treatment [20]. In 2013, Zhang et al. [23] conducted a meta-analysis of 16 previous studies concerning the risk factors for new OCFs after PVP and reported that three significant risk factors (low BMD, low body mass index [BMI], and intradiscal cement leakage) were associated with new OCFs adjacent to the PVP. In addition, Ma et al. [24] conducted an extensive review of 24 studies based on the evidence levels and reported that there were three strong risk factors for new OCFs: (1) lower BMD, (2) intradiscal cement leakage, and (3) vertebral height restoration. They also identified several moderate- to limited-evidence risk factors, such as number of preexisting vertebral fractures, thoraco-lumbar junctions, number of treated vertebrae, greater volume of cement injected, greater kyphotic angle correction, higher initial wedge angle, and higher wedge angle correction. Some clinical trials concluded that development of an adjacentlevel fracture was related to altered biomechanics in the treated spinal area $[6,8,25]$.

Simulation studies using finite element modeling have been considered useful for delineating the pathophysiology of adjacent vertebral fractures to determine the effect of bone cement on treated and non-augmented vertebrae $[12,19,26]$. Apart from using human specimens, finite element modeling has the merits of radical avoidance of individual variability and the easy acquisition of various parameters, such as intradiscal pressure, bone strain, and facet joint contact pressure. Berlemann et al. [12] hypothesized that increased stiffness of the treated vertebrae 
alters the load transfer to the adjacent non-augmented level, thereby resulting in weakening of the spinal unit. Baroud et al. [26] and Polikeit et al. [19] demonstrated that augmented vertebrae reduced the normal cushioning function of the endplate, and consequently, the pressure in the discs and endplate of non-treated vertebrae increased. This increased stress caused by load shifting is likely to place the non-augmented vertebrae at risk of fracture.

We have infrequently encountered single- or doublelevel sandwich constellations in our clinical experience and have been under the impression that this specific situation obviously results in a particular load on the untreated vertebrae because of the stiffening and loss of vertical elasticity of the two adjacent vertebrae. The current study assessed the incidence of adjacent new fractures after twolevel PVP by comparing intervening cases with non-intervening ones. Group 1 included significantly more men. Furthermore, the preoperative wedge angle of the inferior fractured body was significantly higher in group 2 than in group 1. In the cases with OCFs of two consecutive levels, particularly at the thoracolumbar junction, the typical morphological patterns were revealed to have relatively minimal and remarkable height loss in the cephalad fractured body and the caudal fractured body, respectively, thereby contributing to the significant difference in the wedge angle of the inferior fracture body. Other patient demographics and radiological evaluation values had no statistical differences between the two groups. Therefore, group 2 may be at a greater risk than group 1 .

Nonetheless, the results of this study revealed that the difference in the incidence of an adjacent new fracture was statistically significant between group 1 and group 2 $(p=0.030)$. Group 1 had a higher risk of adjacent new fractures than group $2 \mathrm{did}$, and because they were subjected to a double-load shift between two cemented vertebrae, the sandwich constellations were prone to re-fracture after PVP. Furthermore, we attempted to investigate the potential factors contributing to an adjacent new vertebral fracture in sandwich constellations. The patients in group 1 were divided into two subgroups: the adjacent fracture group and the no adjacent fracture group, as presented in Table 4. Of the well-known risk factors for new vertebral compression fracture after PVP, including low BMD, intra-discal PMMA leakage, PMMA volume, surgical approach, age, sex, thoracolumbar junction fracture, IVC, greater kyphotic angle correction, higher initial wedge angle, and higher wedge angle correction, none were sig- nificant risk factors for an adjacent new fracture in a sandwich constellation. This finding suggests that an adjacent new fracture in a sandwich constellation has extremely complex mechanisms compared with those in subsequent OCF after single-level PVP.

There have been only a few studies focusing on this specific type of case [17]. Komemushi et al. [27] investigated the predictors of subsequent fractures using logistic regression analysis and explicitly stated that the presence of a single untreated vertebra between augmented vertebrae was not associated with an increased subsequent fracture rate. However, the incidence of a single-level intervening constellation was approximately $7 \%$ in this study. Retrospective study of Komemushi et al. [27] included 83 patients. Therefore, only as many as six cases may have included patients with a single untreated vertebra between two cemented vertebrae. Their logistic regression analysis results may not have been due to a lack of significance, but instead may have been due to an insufficiently large study population. Another previous remarkable study reported by Wang et al. [18] in 2012 compared the incidence of sandwich vertebral fracture with that of subsequent adjacent-level fractures in patients with multiple compression fractures treated with conservative management approaches. The incidence of sandwich vertebral fracture was $21.43 \%$ (9/42), whereas the incidence of adjacent fractures in the conservative group was $15.49 \%$

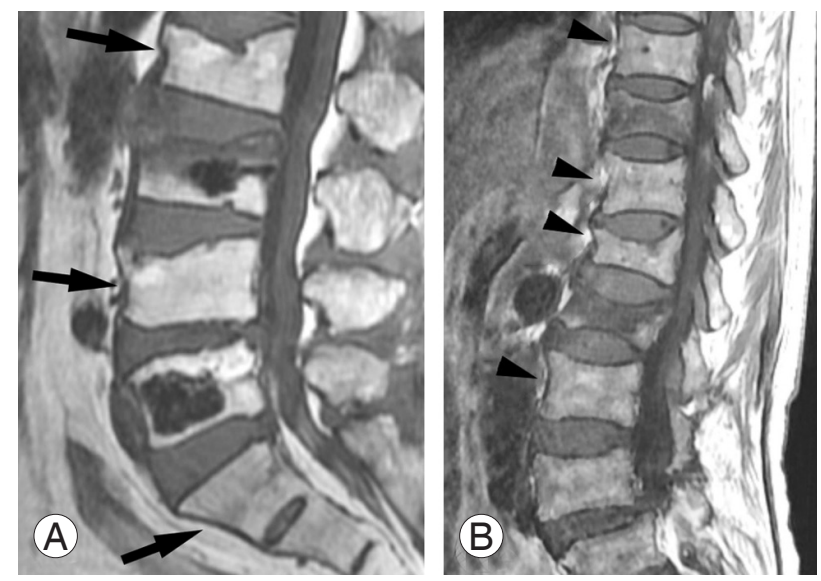

Fig. 4. (A, B) Unfair comparison between the two groups due to differences in the exposure levels to risk. Patients with multiple vertebral compression fractures have more than two adjacent levels as a conservative estimate. All of these adjacent levels (arrowheads in 4B) may be involved in new fracture cases in the development of subsequent new fractures; despite the presence of three adjacent levels (arrows in $4 \mathrm{~A}$ ), only one intervening body may be involved in the sandwiching group. 
(11/71); however, the difference was not significant. Their comparison was confounded by the fact that each group exhibited a difference in risk exposure level. According to a conservative estimate, patients with multiple vertebral compression fractures have more than two adjacent levels. All these adjacent levels (arrowheads) may be involved in new fracture cases in the development of subsequent new fractures; despite the presence of three adjacent levels (arrows), only one intervening body can be involved in the sandwiching group (Fig. 4). New fractures of the adjacent body superior to the upper cemented vertebra and inferior to the lower cemented vertebra were not described or involved. Their study design was able to produce a critical comparison bias. Both the groups in our study were designed to have a similar exposure level to risk. Although we did not find any potential causative radiological factors of subsequent adjacent vertebral fracture in sandwich constellations, Wang et al. [18] reported that during follow-up, only the preoperative kyphotic angulation was positively associated with sandwich vertebral fracture. The difference in results for the factors contributing to new fractures in the sandwiching group or group 1 of our study may also be because of the exposure level of the subjects. Pitton et al. [17] also described the sandwich situations and the secondary fractures of sandwich vertebrae. Their results demonstrated that subsequent fractures in $37.9 \%$ of sandwich vertebrae took a short time to fracture. Despite such a high new fracture rate, they believed that the anatomical situation must not be the only precondition for triggering secondary sandwich fractures. Therefore, there may be some controversy regarding different results from a few previous studies concerning the sandwich constellation.

The current study also has several inherent limitations. First, the investigation was designed as a retrospective review of medical records and images. We were unable to make a more detailed comparison of these complex situations. Second, decreased BMI is a well-known potential risk factor for subsequent OCF after PVP [23,24]. Nevertheless, this study did not characterize the effects of BMI. Third, the volume of injected PMMA was evaluated by reviewing medical records rather than by performing a three-dimensional computed tomography volumetric analysis. This may have introduced bias in the investigation. Finally, the sample size of the study was small because the subjects were restricted to patients with two-level PVPs. Thus, further prospective studies are warranted to define the exact outcomes of this specific and complex condition.

\section{Conclusions}

Although there were no risk factors identified for adjacent new fractures of sandwich constellations in the patient demographics or radiological parameters, sandwich constellations were found to be prone to re-fracture at adjacent levels (29.8\%) because they were subjected to double-load shift. Sandwich constellations can be considered a risk factor for a third OCF after two levels of PVP, and as such, these specific vertebral configurations require more aggressive management for osteoporosis.

\section{Conflict of Interest}

No potential conflict of interest relevant to this article was reported.

\section{References}

1. DePalma MJ, Ketchum JM, Frankel BM, Frey ME. Percutaneous vertebroplasty for osteoporotic vertebral compression fractures in the nonagenarians: a prospective study evaluating pain reduction and new symptomatic fracture rate. Spine (Phila $\mathrm{Pa} 1976$ ) 2011;36:277-82.

2. Klazen CA, Lohle PN, de Vries J, et al. Vertebroplasty versus conservative treatment in acute osteoporotic vertebral compression fractures (Vertos II): an openlabel randomised trial. Lancet 2010;376:1085-92.

3. Masala S, Mastrangeli R, Petrella MC, Massari F, Ursone A, Simonetti G. Percutaneous vertebroplasty in 1,253 levels: results and long-term effectiveness in a single centre. Eur Radiol 2009;19:165-71.

4. Rousing R, Hansen KL, Andersen MO, Jespersen SM, Thomsen K, Lauritsen JM. Twelve-months follow-up in forty-nine patients with acute/semiacute osteoporotic vertebral fractures treated conservatively or with percutaneous vertebroplasty: a clinical randomized study. Spine (Phila Pa 1976) 2010;35:478-82.

5. Tanigawa N, Kariya S, Komemushi A, et al. Percutaneous vertebroplasty for osteoporotic compression fractures: long-term evaluation of the technical and clinical outcomes. AJR Am J Roentgenol 2011;196:1415-8.

6. Grados F, Depriester C, Cayrolle G, Hardy N, De- 
ramond H, Fardellone P. Long-term observations of vertebral osteoporotic fractures treated by percutaneous vertebroplasty. Rheumatology (Oxford) 2000;39:1410-4.

7. Lin EP, Ekholm S, Hiwatashi A, Westesson PL. Vertebroplasty: cement leakage into the disc increases the risk of new fracture of adjacent vertebral body. AJNR Am J Neuroradiol 2004;25:175-80.

8. Trout AT, Kallmes DF, Kaufmann TJ. New fractures after vertebroplasty: adjacent fractures occur significantly sooner. AJNR Am J Neuroradiol 2006;27:217-23.

9. Tseng YY, Yang TC, Tu PH, Lo YL, Yang ST. Repeated and multiple new vertebral compression fractures after percutaneous transpedicular vertebroplasty. Spine (Phila Pa 1976) 2009;34:1917-22.

10. Uppin AA, Hirsch JA, Centenera LV, Pfiefer BA, Pazianos AG, Choi IS. Occurrence of new vertebral body fracture after percutaneous vertebroplasty in patients with osteoporosis. Radiology 2003;226:11924.

11. Ahn Y, Lee JH, Lee HY, Lee SH, Keem SH. Predictive factors for subsequent vertebral fracture after percutaneous vertebroplasty. J Neurosurg Spine 2008;9:129-36.

12. Berlemann U, Ferguson SJ, Nolte LP, Heini PF. Adjacent vertebral failure after vertebroplasty: a biomechanical investigation. J Bone Joint Surg Br 2002;84:748-52.

13. Dublin AB, Hartman J, Latchaw RE, Hald JK, Reid $\mathrm{MH}$. The vertebral body fracture in osteoporosis: restoration of height using percutaneous vertebroplasty. AJNR Am J Neuroradiol 2005;26:489-92.

14. Kim SH, Kang HS, Choi JA, Ahn JM. Risk factors of new compression fractures in adjacent vertebrae after percutaneous vertebroplasty. Acta Radiol 2004;45:440-5.

15. Lee WS, Sung KH, Jeong HT, et al. Risk factors of developing new symptomatic vertebral compression fractures after percutaneous vertebroplasty in osteoporotic patients. Eur Spine J 2006;15:1777-83.

16. Voormolen $\mathrm{MH}$, Lohle PN, Juttmann JR, van der Graaf Y, Fransen H, Lampmann LE. The risk of new osteoporotic vertebral compression fractures in the year after percutaneous vertebroplasty. J Vasc Interv Radiol 2006;17:71-6.
17. Pitton MB, Herber S, Bletz C, et al. CT-guided vertebroplasty in osteoprotic vertebral fractures: incidence of secondary fractures and impact of intradiscal cement leakages during follow-up. Eur Radiol 2008;18:43-50.

18. Wang L, Yang H, Shi Y, Luo Z, et al. Sandwich vertebral fracture in the study of adjacent-level fracture after vertebral cement augmentation. Orthopedics 2012;35:e1225-30.

19. Polikeit A, Nolte LP, Ferguson SJ. The effect of cement augmentation on the load transfer in an osteoporotic functional spinal unit: finite-element analysis. Spine (Phila Pa 1976) 2003;28:991-6.

20. Lee DG, Park CK, Park CJ, Lee DC, Hwang JH. Analysis of risk factors causing new symptomatic vertebral compression fractures after percutaneous vertebroplasty for painful osteoporotic vertebral compression fractures: a 4-year follow-up. J Spinal Disord Tech 2015;28:E578-83.

21. McKiernan F, Faciszewski T, Jensen R. Reporting height restoration in vertebral compression fractures. Spine (Phila Pa 1976) 2003;28:2517-21.

22. Teng MM, Wei CJ, Wei LC, et al. Kyphosis correction and height restoration effects of percutaneous vertebroplasty. AJNR Am J Neuroradiol 2003;24:1893900 .

23. Zhang Z, Fan J, Ding Q, Wu M, Yin G. Risk factors for new osteoporotic vertebral compression fractures after vertebroplasty: a systematic review and metaanalysis. J Spinal Disord Tech 2013;26:E150-7.

24. Ma X, Xing D, Ma J, et al. Risk factors for new vertebral compression fractures after percutaneous vertebroplasty: qualitative evidence synthesized from a systematic review. Spine (Phila Pa 1976) 2013;38:E713-22.

25. Fribourg D, Tang C, Sra P, Delamarter R, Bae H. Incidence of subsequent vertebral fracture after kyphoplasty. Spine (Phila Pa 1976) 2004;29:2270-6.

26. Baroud G, Nemes J, Heini P, Steffen T. Load shift of the intervertebral disc after a vertebroplasty: a finiteelement study. Eur Spine J 2003;12:421-6.

27. Komemushi A, Tanigawa N, Kariya S, et al. Percutaneous vertebroplasty for osteoporotic compression fracture: multivariate study of predictors of new vertebral body fracture. Cardiovasc Intervent Radiol 2006;29:580-5. 